\title{
FRICTION MODELING OF AL-MG ALLOY SHEETS BASED ON MULTIPLE REGRESSION ANALYSIS AND NEURAL NETWORKS
}

\author{
Hirpa Gelgele Lemu' ${ }^{1}$, Tomasz Trzepieciński ${ }^{2}$, Andrzej Kubit ${ }^{3}$, Romuald Fejkiel ${ }^{4}$
}

1 Faculty of Science and Technology, University of Stavanger, N-4036 Stavanger, Norway, e-mail: hirpa.g.lemu@ uis.no

2 Department of Materials Forming and Processing, Rzeszow University of Technology, Al. Powstańców Warszawy 8, 35-959 Rzeszów, Poland, e-mail: tomtrz@prz.edu.pl

${ }^{3}$ Department of Manufacturing and Production Engineering, Rzeszow University of Technology, Al. Powstańców Warszawy 8, 35-959 Rzeszów, Poland, e-mail: akubit@prz.edu.pl

${ }^{4}$ Stanisław Pigon State School of Higher Vocational Education in Krosno, ul. Rynek 1, $38-400$ Krosno, Poland, e-mail:rfejkiel@wp.pl

Received: 2016.12 .15

Accepted: 2017.02.01

Published: 2017.03.01

\begin{abstract}
This article reports a proposed approach to a frictional resistance description in sheet metal forming processes that enables the determination of the friction coefficient value under a wide range of friction conditions, without performing timeconsuming experiments. The motivation for this proposal is the fact that there exists a considerable amount of factors that affect the friction coefficient value and as a result building analytical friction model for specified process conditions is practically impossible. In this proposed approach, a mathematical model of friction behaviour is created using multiple regression analysis and artificial neural networks. The regression analysis was performed using a subroutine in MATLAB programming code and STATISTICA Neural Networks was utilized to build an artificial neural networks model. The effect of different training strategies on the quality of neural networks was studied. As input variables for regression model and training of radial basis function networks, generalized regression neural networks and multilayer networks, the results of strip drawing friction test were utilized. Four kinds of Al-Mg alloy sheets were used as a test material.
\end{abstract}

Keywords: coefficient of friction, friction, GRNN, neural networks, RBF network, sheet metal forming.

\section{INTRODUCTION}

Regression modelling is one of the most often used methods to solve problems in engineering, economics and management science [10, 17, 18]. For instance, mathematical models are utilized to characterize the relationship and to predict possible fault patterns based on the process conditions in the spot welding process [14] and to find an input-output relationship in a tungsten inert gas welding process [7]. On the other hand, the wide field of application of the regres- sion analysis proves there exists no unequivocal definition of regression term [10]. According to Cohen et al. [4] multiple regression analysis is highly general and, therefore, it is a very flexible data-analytic system that may be used whenever a dependent variable is to be studied as a function of, or in relationship to, any factors of interest expressed as independent variables. In other words, an advantage of regression in scientific research concerns the possibility of predicting the value of a dependent random variable based on the values of other independent variables and 
establishing a functional relation of the statistical nature. The mathematical complexity of the model and the degree to which it is a realistic model depends on how much is known about the process being studied and on the purpose of the modelling task. A causal analysis allows us to separate the effect of independent variables on the dependent variables so the unique contribution of each variable can be examined. Alternative approaches to stochastic analysis are artificial neural networks (ANNs) which allows us to overcome the difficulty arising in the assessment of the complex relationships that is established based on empirical analytical models and is based on the empirical non-analytical models. Many ANN architectures have been developed to realize the regression and classification tasks. The most widespread ones are Kohonen's networks, Multilayer Perceptron (MLP), Radial Basis Function (RBF) and Generalized Regression Neural Networks (GRNN).

Application of ANNs is widely reported in the literature. Aleksendrić et al. [1] used ANN to predict the recovery performance of brake friction materials. The prediction of tribological properties of plasma nitride $316 \mathrm{~L}$ stainless steel using ANN has been studied by Yetim et al. [25]. Gyurova and Friedrich [8] have also predicted sliding friction and wear properties of polyphenylene sulphide composites. ANN are also used to model and optimize the surface roughness in single point incremental forming [12]. Among the widespread usage of regression analysis in tribology, it is necessary to put special emphasis on the possibility of the determination of the friction co-efficiency [20] and the determination of the wear rate for different combinations of load, grit size, and sliding distance $[5,13,24]$. To develop a contact area ratio expression regarding the nominal pressure, the friction coefficient and relative sliding of the MATLAB programme was utilized [15]. Regression equations have led to modelling and predicting the film thickness in contact conditions under the elastohydrodynamic lubrication
$[11,16]$. A multiple regression model was applied to analyse the influence of different parameters on the springback phenomenon in the sheet metal forming process [6].

Many authors with a huge success applied ANNs to nonlinear regression analysis. For instance, application of ANN allowed them to find the relationships between the value of the surface roughness parameters and real contact area under the different friction conditions [19]. Many researchers applied the ANN models to predict flow curves in a single step deformation on several materials [3]. An ANN may solve problems by learning rather than by a specific programming based on well-defined rules [9].

Friction behaviour in sheet metal forming processing depends on several parameters such as contact pressure, sliding velocity, sheet metal and tool surface roughness, tool material and lubricant condition. Furthermore, recent studies of authors $[13,14]$ show that the topography of a surface influences the frictional behaviour of a contact surface and hence its wear. Hence, there is a need to understand better the role of friction and to find factors that essentially influence the friction coefficient values. In this article, the classical regression and different architectures of neural networks are implemented to modelling the friction of Al-Mg alloy sheets. To determine the friction coefficient value, the simple strip-drawing test is realized and the efficiency of different training strategies was studied.

\section{MULTIPLE REGRESSION MODEL}

The regression model was built based on the results of strip-drawing tests under lubricated conditions. The aim of the performed experiments was to find the correlation between the value of surface roughness parameters of the sheet metal and rolls as well as the load pressure on the friction coefficient value. The specimens for the friction tests were made of brass sheet metal and were prepared as strips measuring 20

Table 1. Characteristics of tested materials and value of parameters varied during the test

\begin{tabular}{|c|c|c|c|c|c|}
\hline Material & $\mathrm{R}_{\mathrm{e}}(\mathrm{MPa})$ & $\mathrm{Ra}^{0}(\mu \mathrm{m})$ & $\mathrm{Ra}^{90}(\mu \mathrm{m})$ & $\mathrm{Ra}^{r}(\mu \mathrm{m})$ & $\mathrm{F}_{\mathrm{C}}[\mathrm{kN}]$ \\
\hline AA5251 H14 & 211.0 & 0.22 & 0.28 & 0.32 & 0.8 \\
\hline AA5754 H14 & 211.8 & 0.29 & 0.36 & 0.63 & 1.2 \\
\hline AA5754 H18 & 185.4 & 0.26 & 0.32 & 1.25 & 1.6 \\
\hline AA5754 H24 & 165.8 & 0.18 & 0.24 & 2.5 & 2 \\
\hline
\end{tabular}


a)

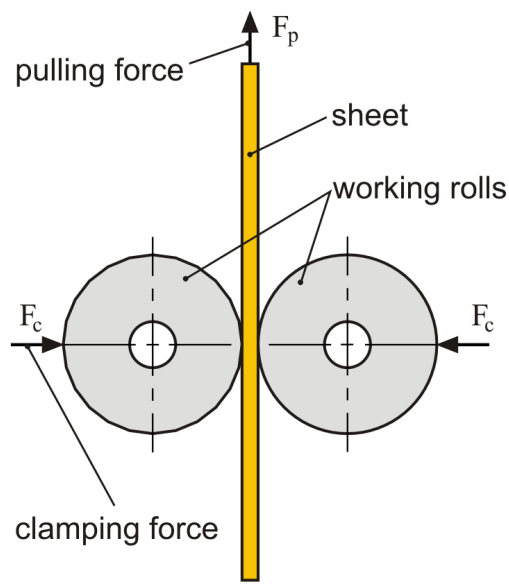

b)

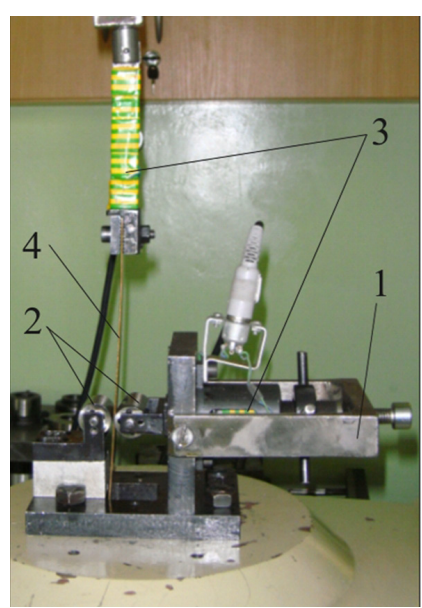

Fig. 1. a) Schematic of strip drawing friction test; b) View of the testing device mounted in universal testing machine: 1 - base, 2 - working rolls, 3 - strain gauges, 4 - specimen

$\mathrm{mm}$ in width and about $200 \mathrm{~mm}$ in length, cut along the rolling direction of the sheet. The tests were performed using the values of roll surface roughness $\left(\mathrm{Ra}^{\mathrm{r}}\right)$ and clamping force $\left(\mathrm{F}_{\mathrm{C}}\right)$ given in Table 1.

The mechanical properties of the sheet metal are the main parameters influencing the phenomena that exist between asperities of contact bodies. The value of yield stress $R_{e}$ (Table 1 ) is determined in the uniaxial tensile test. The given clamping force values are approximated. Application of different values of clamping force allows us to build a data set with the wide range of input signals. The sliding velocity was set to $2 \mathrm{~mm} / \mathrm{s}$. The test conducted in such a way that a strip of the sheet was clamped with specified force between two cylindrical rolls of equal radii (Fig. 1a). The experimental setup is also shown in Figure 1b.

The rolls were made of cold working tool steel. Then when the displacement of moving crosshead of testing machine was engaged, the pulling force and clamping force were recorded continuously using a load cell and a computer programme. The coefficient of friction $\mu$, defined as a ratio of the results of the clamping force $F_{c}$ and pulling force $F_{p}$, was determined using the relationship $\mu=\mathrm{F}_{\mathrm{p}} / 2 \mathrm{~F}_{\mathrm{c}}[20]$. Surface roughness parameters were measured by using Taylor Hobson Surtronic 3+ instrument to determine arithmetic average height along the rolling $\left(\mathrm{Ra}^{0}\right)$ and transverse directions $\left(\mathrm{Ra}^{90}\right)$ of the sheet metal. The arithmetic average height parameter of rolls was measured along the generating line of the roll.

Selecting the factors that have influence on frictional resistance of a sheet metal is necessary to take into consideration the requirements that are related with the construction of the regression model. These requirements boil down to the selection of factors that significantly influence the frictional resistance and are simultaneously independent. Significance of requirement of particular factors may be verified using elimination by a posteriori method on the later stage of model building. As the independent variables, the clamping force of the rolls and surface roughness parameters of sheet metal and rolls were taken into consideration. All tested materials were tested for all combinations of variation of surface roughness parameters of the rolls and clamping forces. A matrix of independent variables was built on the basis of 80 observations (i.e. $\mathrm{n}=80$ ).

The selection of multiple regression model by a posteriori method was carried out by subroutine in MATLAB +SIMULINK package. MAT$L A B$ is a high-level computer language for scientific application based on matrix formulation. The advantage of an interactive system is that programs can be tested and debugged quickly, allowing the user to concentrate more on the principles behind the program and less on programming itself. Furthermore, MATLAB subroutines can be developed in a much shorter time than equivalent FORTRAN or $\mathrm{C}$ programs. The elementary assumptions and methods creation of multiple regression model are introduced below (Equation 1). The linear regression model with $p$ independent variables $\mathbf{X}$ and one dependent variable $\mathbf{Y}$ was established. In further considerations, it is necessary to determine if the received model is a good predictor. So the model 
can be written as [21]:

$$
\mathrm{Y}=\mathrm{X} \beta+\varepsilon
$$

where: $\mathrm{Y}$ - vector of observations on the dependent variable $Y_{i}(n \times 1), X$ - matrix consisting of a column of ones, which is labelled 1 , followed by the $\mathrm{p}$ column vectors of the observations on the independent variables $(n \times p), \beta-$ vector of parameters to be estimated $(p \times 1), \quad \varepsilon-$ random terror vector $(\mathrm{n} \times 1)$.

The vector of residuals $\varepsilon$ reflects the lack of agreement between the observed $\mathrm{Y}$ and the estimated $\hat{Y}$ :

$$
\varepsilon_{\mathrm{i}}=\mathrm{Y}_{\mathrm{i}}-\hat{\mathrm{Y}}_{\mathrm{i}}
$$

The subscript $i$ denotes the observational unit from which the observations on $\mathrm{Y}$ and the $\mathrm{p}$ independent variables were taken. The conventional tests of hypotheses and confidence interval estimates of the parameters are based on the assumption that the estimates are normally distributed. Thus, the assumption of normality of the $\varepsilon_{\mathrm{i}}$ is critical for these purposes. However, normality is not required for the least squares estimation. The expected value of random error $\mathrm{E}(\varepsilon)=0$ and variance $\mathrm{D}^{2}(\varepsilon)=\mathrm{I} \sigma^{2}=0$, where $\mathrm{I}$ is a unit matrix, so the elements $\varepsilon$ must be non-correlated [2]. Because $\mathrm{E}(\varepsilon)=0$ the other way of describing the model is as follows:

$$
\mathrm{E}(\mathrm{Y})=\mathrm{X} \beta
$$

Then, the sum of squares is equal to:

$$
\mathrm{E}(\mathrm{Y})=\mathrm{X} \beta
$$

The value of estimator $\beta$ obtained by the least squares method is equal to $b$ which after substituting into Equation 2 minimizes to $\varepsilon$ ' $\varepsilon$.

For the four independent variables, four estimators of parameters $\beta_{\mathrm{i}}, \quad\{\mathrm{i} \in \mathrm{N}: 0<\mathrm{i}<5\}$ are sought, which are determined by the well-known least square estimation. Values of estimators $b_{i}$, $\{i \in \mathrm{N}: 0<\mathrm{i}<5\}$ are expressed as:

$$
\mathrm{b}=\left(\mathrm{X}^{\mathrm{T}} \mathrm{X}^{-1} \mathrm{X}^{\mathrm{T}}\right) \mathrm{Y}
$$

If several normal equations depend on other equations then a matrix $\mathrm{X}^{\mathrm{T}} \mathrm{X}$ is singular, so $\left(\mathrm{X}^{\mathrm{T}} \mathrm{X}\right)^{-}$ ${ }^{1}$ does not exist. Then a smaller number of parameters need to be taken into account in the model. The values of estimators can be obtained by least square estimation under the assumption that:

- the form of the model is linear,

- received factors influenced on the friction coefficient value are not random and they are in- dependent from each other,

- the number of received factors to create the regression model are less than the number of observations,

- the determinant of matrix $X^{\mathrm{T}} X \neq 0$ otherwise $\mathrm{X}^{\mathrm{T}} \mathrm{X}$ are non-singular,

- $\varepsilon_{\mathrm{i}}$ is a random variable with the advisable value equals to 0 .

Elements of vector $\mathrm{b}$ are the linear functions of observations $\mathrm{Y}_{\mathrm{i}}, \mathrm{i} \in\langle 1, \mathrm{n}\rangle$ and provide unbiased estimates of the elements of $\beta$ which have the minimum variance irrespective of distribution properties of the errors.

The vector of estimated means of the dependent variable $\mathrm{Y}$ for the values of the independent variables in the data set is computed as:

$$
\hat{\mathrm{Y}}=\mathrm{Xb}
$$

After determination of $\mathrm{b}$ and combination with Equation 6, the regression equation gets the form:

$$
\hat{Y}=X\left[\begin{array}{c}
-0.06291 \\
0.000399 \\
1.386871 \\
-0.59603 \\
-0.0056 \\
-0.02768
\end{array}\right]
$$

Upon relating the center matrix to the mean values, we find $\mathrm{j} \times \mathrm{y}$ square matrix . Determining the elements of correlation matrix with factors from the interval $(0,1)$, the correlation matrix becomes:

$$
\mathbf{r}_{\mathrm{jy}}=\frac{\mathbf{s}_{\mathrm{jy}}}{\sqrt{\mathbf{s}_{\mathrm{jj}} \cdot \mathbf{s}_{\mathrm{yy}}}}
$$

$\mathbf{R}=\left[\begin{array}{ccccc}1 & 0.953 & 0.019 & 0.006 & 0.588 \\ 0.953 & 1 & -0.008 & 0.013 & 0.673 \\ 0.019 & -0.008 & 1 & 0.005 & 0.455 \\ 0.006 & 0.013 & 0.005 & 1 & -0.406 \\ 0.588 & 0.673 & 0.455 & -0.406 & 1\end{array}\right]$

Useful statistics to check is a $\mathrm{R}^{2}$ value of a regression fit, which measures the proportion of total variation about the mean $Y_{\mathrm{sr}}$ explained by the regression and it is defined by:

$$
R^{2}=1-\frac{\sum_{i}\left(\hat{Y}_{i}-Y_{s r}\right)^{2}}{\sum_{i}\left(Y_{i}-Y_{s r}\right)^{2}}
$$


Table 2. Results of analysis of variance

\begin{tabular}{|l|c|c|c|c|}
\hline $\begin{array}{c}\text { Source of } \\
\text { variation }\end{array}$ & $\begin{array}{c}\text { Degrees } \\
\text { of free- } \\
\text { dom }\end{array}$ & $\begin{array}{c}\text { Sum of } \\
\text { squares }\end{array}$ & $\begin{array}{c}\text { Mean } \\
\text { square }\end{array}$ & Total F \\
\hline Generally & 79 & 0.086175 & & \\
\hline Regression & 5 & 0.071845 & 0.014369 & 74.2008 \\
\hline Residue & 74 & 0.01433 & 0.000194 & \\
\hline
\end{tabular}

Where both summations are over $i=1,2, \ldots$, $\mathrm{n}$. Factor $R^{2}$ is called the square of the multiple correlation coefficient and shall take the values as high as 1 .

The larger the value of $R^{2}$, the better the fitted equation can explain the variation in the data. Assigned regression model has $R^{2}=0.83371$ implying that $83.371 \%$ of the sums of squares can be associated with the variation in these four independent variables. According to the literature, the model with $R^{2}$ above $80 \%$ may be acknowledged as a good predictor [23]. Analysis of variation (Table 2) can be used to check the fitness of friction model and to identify the main effects of design variables.

Therefore, the variation allows determination of uncertainties related with prognosis of variable values. Variance as a mean square deviation of random variables from their mean value is a measure of a dispersion effect of the probable variable value and it is an irreplaceable testing tool of significance of the whole model. Under the significance level of $\alpha=0.05$ the total value of F-test (Fischer - Snedecor's test) of 74.2008 that exceeds the value of $F=2.33$, as read from tables of F-test, confirmed that Equation 4 is a good predictor. Significance level is called a probability of a mistake during the estimation of parameter significance that is its probability to indicate the incorrect estimate of the whole model. Usually the significance level is assumed equal to 0.05 .
In the case of lower values, it often occurs that after the estimate of significance level of a parameter, it appears that the significance does not have a sufficiently high level. The higher level of probability may cause that a computed parameter, despite positive significance test, does not fulfil theoretical assumptions of the regression method. The number of degrees of freedom related with each sum of squares exhibits how much independent information is included in the $\mathrm{n}$ independent values $\mathrm{Y}_{\mathrm{i}},\{\mathrm{i} \in \mathrm{N}: 0<\mathrm{i}<\mathrm{n}\}$ is needed to specify a sum of squares.

In order to obtain the best prediction quality of the regression equation, as many variables as possible should be considered. It can be related the with building of a database of lots of observations and the involved variables in the regression model so that it is possible to analyze the number of variables as low as possible. The compromise between these contradictory conditions is the selection procedure of the best regression equation. The lowest value of partial F-test (Table 3 ) is higher than the value read out from the regression table at $\mathrm{F}=2.50$ under the significance level $\alpha=0.05$. Because the obtained F-test value for variable $\mathrm{X}_{1}$ is higher than the critical value, it can be accepted that the equation $\hat{Y}=f\left(X_{1}, X_{2}, X_{3}, X_{4}, X_{5}\right)$ is a final regression model. To ensure better prediction, the model may be improved, for example, by increasing the input variables or introducing mixed components $\mathrm{X}_{1} * \mathrm{X}_{2}, \mathrm{X}_{1} * \mathrm{X}_{3}$ etc. However, taking into account high value of square of the multiple correlation coefficient $\mathrm{R}^{2}=83.371 \%$ and lower value of the standard deviation factor of 0.016 the model was accepted as adequate.

The results of partial F-test value (Table 3) determined after rejection from the regression model confirmed the significance of all variables. However, the highest value of partial Ftest is observed after rejection of $\mathrm{Ra}^{0}$ roughness parameter, so this parameter exhibits the smallest in formativeness.

Table 3. Results of partial F-test analysis

\begin{tabular}{|c|c|c|c|c|}
\hline Source of variation & Degrees of freedom & Sum of squares & Mean square & Partial $F$ \\
\hline$R^{2} F_{r}=s s i o n$ & 5 & 0.071845 & & \\
\hline due to $\mathrm{R}_{\mathrm{e}} \mid \mathrm{Ra}^{0}, \mathrm{Ra}^{90}, \mathrm{Ra}^{r}, \mathrm{~F}_{\mathrm{C}}$ & 1 & 0.003525 & 0.003525 & 18.20079 \\
\hline due to $\mathrm{Ra}^{0} \mid \mathrm{R}_{\mathrm{e}}, \mathrm{Ra}^{90}, \mathrm{Ra}^{r}, \mathrm{~F}_{\mathrm{C}}$ & 1 & 0.025912 & 0.025912 & 133.8073 \\
\hline due to $\mathrm{Ra}^{90} \mid \mathrm{R}_{\mathrm{e}}, \mathrm{Ra}^{0}, \mathrm{Ra}^{r}, \mathrm{~F}_{\mathrm{C}}$ & 1 & 0.013834 & 0.013834 & 71.43959 \\
\hline due to $\mathrm{Ra}^{r} \mid \mathrm{R}_{\mathrm{e}}, \mathrm{Ra}^{0}, \mathrm{Ra}^{90}, \mathrm{~F}_{\mathrm{c}}$ & 1 & 0.00175 & 0.00175 & 9.038703 \\
\hline due to $\mathrm{F}_{\mathrm{C}} \mid \mathrm{R}_{\mathrm{e}}, \mathrm{Ra}^{0}, \mathrm{Ra}^{90}, \mathrm{Ra}^{r}$ & 1 & 0.016713 & 0.016713 & 86.30279 \\
\hline $\mathrm{Residual}$ & 74 & 0.01433 & 0.000194 & \\
\hline
\end{tabular}


a)

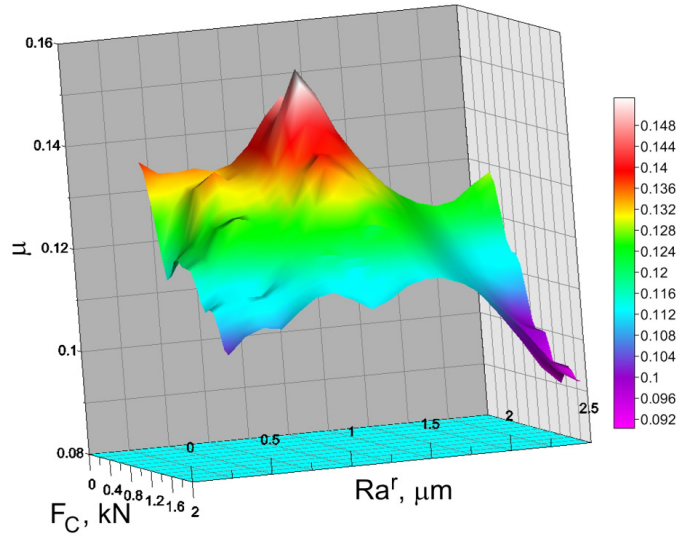

b)

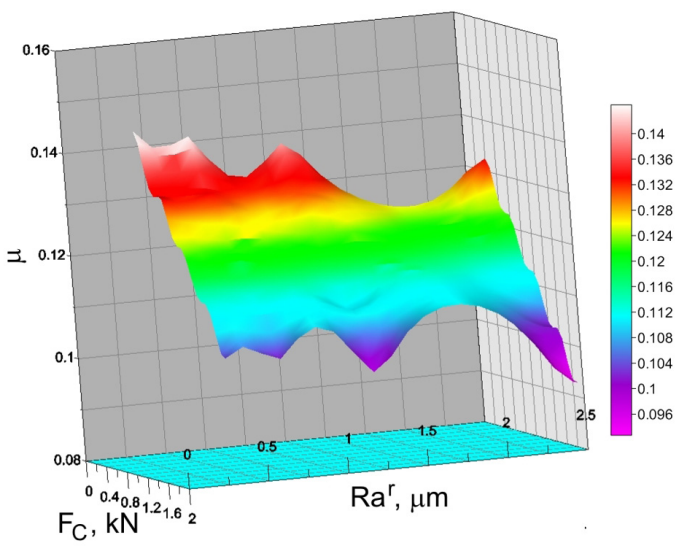

Fig. 2. Value of friction coefficient value for AA5754 H18 sheet metal: a) determined experimentally; b) predicted by regression model

Figure 2 shows comparison of the values of the friction coefficient for AA5754 H18 sheet metal. As shown in the two plots, it compares the values determined by experimental work (Figure $2 a)$ and those predicted by the regression model. It is possible to observe that the multiple regression model has greater smoothing properties of data, while the results of experimental study of the friction coefficient value for particular sets of input variables may possess systematic errors.

\section{NETWORKS MODELS}

To build different network models, the Statistica Neural Networks (SNN) were used and diverse networks such as MLPs, RBFs and GRNNs were employed to analyse the data. Next, the network that shows the best performance for the analysed types of ANNs was selected. The methodology of creating MLP for the prediction of value of friction co-efficiency is presented in other works of the authors $[20,23]$. The input variables corresponded to the variables used to calculate the classical regression equation (see Section 2). The most important parameter from input variables is roughness parameter $\mathrm{Ra}^{0}$ (Table 4 ). The yield stress value exhibits the smallest effect on the value of friction co-efficiency. A measure of the sensitivity of the network is the value of error indicated the quality of the network in the case of absence of a given variable. The more important input parameter in the learning or validation process, the greater the value of the error.

As illustrated in Fig. 3, the RBF networks consisted of three layers. The radial activation functions are implemented in the hidden layer of neurons.

It is most often a Gaussian function:

$$
\mathbf{G}(i, \boldsymbol{x})=\exp \left(-\frac{\left\|x-C_{i}\right\|^{2}}{2 \sigma_{i}^{2}}\right)
$$

where: $\|\cdot\|$ stands for Euclidean norm and $s_{i}$ is a parameter determining the shape of radial function.

Radial networks are composed of neurons whose activation functions can be realized using the representation given in the following equation (12):

$$
x \rightarrow \varphi(\|x-c\|), x \in R^{n}
$$

The functions $\varphi(\|\mathrm{x}-\mathrm{c}\|)$ are called the radial basis functions. Their values change radially around the center c. RBF networks can model any non-linear function with using a single hidden layer [22].

Table 4. The importance of input variables determined for training set

\begin{tabular}{|c|c|c|c|c|c|}
\hline \multirow{2}{*}{ Parameter } & \multicolumn{5}{|c|}{ Variables } \\
\cline { 2 - 6 } & $\mathrm{R}_{\mathrm{e}}$ & $\mathrm{Ra}^{0}$ & $\mathrm{Ra}^{90}$ & $\mathrm{Ra}^{\mathrm{r}}$ & $\mathrm{F}_{\mathrm{C}}$ \\
\hline Rank & 5 & 1 & 2 & 3 & 4 \\
\hline Error & 0.0155 & 0.04519 & 0.0365 & 0.03361 & 0.01941 \\
\hline Ratio & 1.296299 & 3.779331 & 3.052333 & 2.810585 & 1.623423 \\
\hline
\end{tabular}


Furthermore, the linear transformation occurring in the output layer can be optimized using traditional linear modelling techniques. Consequently, during the learning process of RBF network no local minima occur. They are basic problems during the learning of MLP. RBF networks can be learnt in a very short time compared with that of MLPs.

In the process of training RBF networks, the selection of weights of a hidden layer with an output layer comes down to solving the following equation:

$$
\mathrm{G}^{\prime} \mathrm{w}=\mathrm{y}^{\mathrm{d}}
$$

where: $\mathrm{w}$ - sought weights matrix, G'- response matrix of hidden layer on all training vectors, $\mathrm{y}^{\mathrm{d}}$ - a matrix of desired responses for all training vectors.

The solution of Equation 13 can be obtained by minimizing the square of the norm or absolute value $\left\|y^{d}-w G^{\prime}\right\|$.

GRNNs, which is one of a Bayesian type network $[1,17]$, is used for a generalized regression purpose. The network consists of 4 functionally different layers: input, radial (for storing centers), regression and output layers. GRNNs use the method of nuclear approximation in order to realize regression. In GRNNs the Gaussian nuclear functions are arranged in each neurons of hidden layers in such a way that, for each case of training set, there exists one neuron that spans over the case and that is an appropriate Gaussian function. In the GRRNs the radial neurons represent clus-

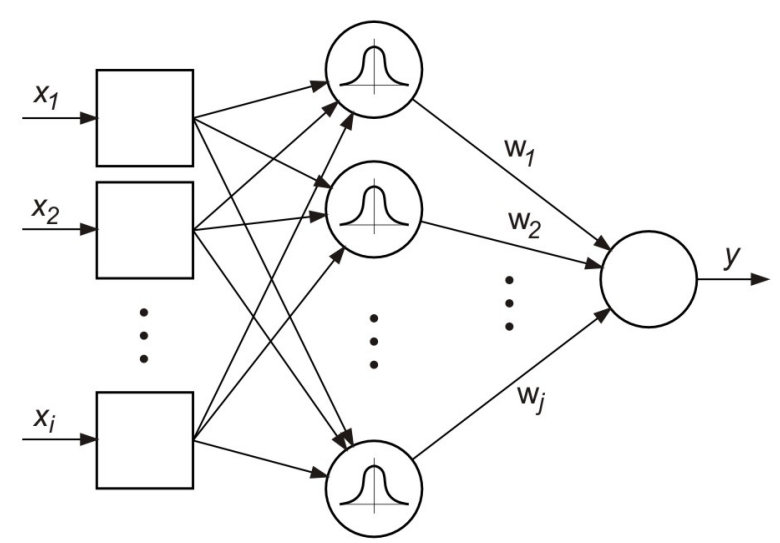

Fig. 3. The architecture of RBF network

ters, not isolated training cases. The algorithm tests each case, assigns it to the nearest radial neuron, and determines the weights for neurons that appear in the third layer. It computes the sum of the values of output variables and the counting of cases assigned to specific cluster.

In order to scale the data to the suitable range minimax procedure [22], which automatically determine the scale factors, were selected. The number of training samples in the training set (TS) was 64 . The training set consists of values of input variables and corresponds to the value of the friction coefficient. For the purpose of keeping an independent check on the progress of the BP algorithm, all observations were randomly separated from the validation set (VS) which contains 16 training pairs ( $20 \%$ of all training samples).

Table 5. Regression statistics for MLP 5:5-11-1:1

\begin{tabular}{|c|c|c|c|c|c|c|c|c|}
\hline \multirow{3}{*}{ Parameter } & \multicolumn{8}{|c|}{ Learning algorithm } \\
\hline & \multicolumn{2}{|c|}{$\begin{array}{c}\text { Back } \\
\text { Propagation }\end{array}$} & \multicolumn{2}{|c|}{$\begin{array}{l}\text { Conjugate } \\
\text { Gradients }\end{array}$} & \multicolumn{2}{|c|}{ Quasi Newton } & \multicolumn{2}{|c|}{ Levenberg-Marquardt } \\
\hline & TS & VS & TS & VS & TS & VS & TS & VS \\
\hline Error Mean & -0.0019 & 0.0011 & 0.0001 & 0.0033 & 0.0033 & 0.0062 & -0.0028 & -0.0004 \\
\hline Error S.D. & 0.0110 & 0.0106 & 0.0198 & 0.0216 & 0.0143 & 0.0139 & 0.0135 & 0.0118 \\
\hline ABS Error Mean & 0.0086 & 0.0090 & 0.0166 & 0.0185 & 0.0123 & 0.0127 & 0.0107 & 0.0097 \\
\hline S.D. Ratio & 0.3403 & 0.2919 & 0.6126 & 0.5930 & 0.4411 & 0.3815 & 0.4185 & 0.3241 \\
\hline Correlation & 0.9480 & 0.9623 & 0.7920 & 0.8159 & 0.9077 & 0.9407 & 0.9098 & 0.9506 \\
\hline
\end{tabular}

Table 6. Regression statistics for RBF 5:5-14-1:1

\begin{tabular}{|l|c|c|c|c|c|c|c|c|}
\hline \multirow{3}{*}{ Parameter } & \multicolumn{9}{|c|}{ Learning algorithm } & \multicolumn{2}{c|}{ Levenberg-Marquardt } \\
\cline { 2 - 9 } & \multicolumn{2}{|c|}{$\begin{array}{c}\text { Back } \\
\end{array}$} & Propagation & \multicolumn{2}{c|}{$\begin{array}{c}\text { Conjugate } \\
\text { Gradients }\end{array}$} & \multicolumn{2}{c|}{ Quasi Newton } & \multicolumn{2}{c|}{ VS } & VS \\
\cline { 2 - 9 }$y$ & TS & VS & TS & VS & TS & VS & TS & V \\
\hline Error Mean & -0.0019 & 0.0017 & $6.026 \mathrm{E}-5$ & 0.0027 & -0.0004 & 0.00324 & 0.00021 & 0.00160 \\
\hline Error S.D. & 0.0167 & 0.0201 & 0.0155 & 0.0185 & 0.0167 & 0.0208 & 0.0176 & 0.0209 \\
\hline ABS Error Mean & 0.0131 & 0.0166 & 0.0119 & 0.0160 & 0.0129 & 0.0173 & 0.0146 & 0.0158 \\
\hline S.D. Ratio & 0.5157 & 0.5505 & 0.4807 & 0.5090 & 0.5151 & 0.5712 & 0.5446 & 0.5747 \\
\hline Correlation & 0.8573 & 0.8387 & 0.8768 & 0.8678 & 0.8604 & 0.8345 & 0.8408 & 0.8188 \\
\hline
\end{tabular}


Table 7. Regression statistics for GRNN 5:5-64-1:1

\begin{tabular}{|l|c|c|}
\hline \multicolumn{1}{|c|}{ Parameter } & TS & VS \\
\hline Error Mean & -0.00010 & 0.00043 \\
\hline Error S.D. & 0.0083 & 0.0096 \\
\hline ABS Error Mean & 0.0051 & 0.0069 \\
\hline S.D. Ratio & 0.2578 & 0.2650 \\
\hline Correlation & 0.9678 & 0.9698 \\
\hline
\end{tabular}

Different training algorithms were used to train the networks, namely Back Propagation (BP), Conjugate Gradients (CG), Quasi Newton (QN) and Levenberg-Marquardt (LM). In the case of GRNNs, only the training of generalized regression method is available in SNN. The BP algorithm was used with the following settings: learning rate value was 0.1 and momentum value was set to 0.3 [21]. The quick propagation algorithm was used with the following settings: learning rate value was 0.1 and acceleration value was set to 2 [22]. As a criterion to stop the training process, the value of the Root-Mean-Square (RMS) error for validation set was used where the error shows no more decreasing trend. The one network with the best performance for the analysed types of ANNs was selected to compare the regression statistics (Tables 5 to Table 7).
Factors necessary to estimate the regression model are [22]: data standard deviation ratio (S.D. Ratio) and the standard Pearson-R coefficient between the target and actual outputs values. These factors are independently determined for all sets. For a very good model the value of S.D. Ratio amounts to less than 0.1 .

It is observed that the used training algorithms has a great impact on the correlation coefficient and S.D. ratio. In the case of MLP network (Table 5 ), the highest performance is received for the network trained using back propagation algorithm. The high efficiency of the learning process is confirmed by the value of correlation coefficient for verification set that is higher than the training set.

In the case of the RBF network (Table 6), the Conjugate Gradients was the most efficient training method. Generally, correlation coefficient and S.D. ratio values for RBF network are very similar for all training algorithms. The values of S.D. ratio (up to 0.48 ) represent the ability of RBF network to analyse the regression problems. The best regression results were found for GRNN network (Table 7). The high value of correlation coefficient (up to 0.96 ) and the value of S.D. ratio of about 0.25 testify to the good regression properties of GRNN.

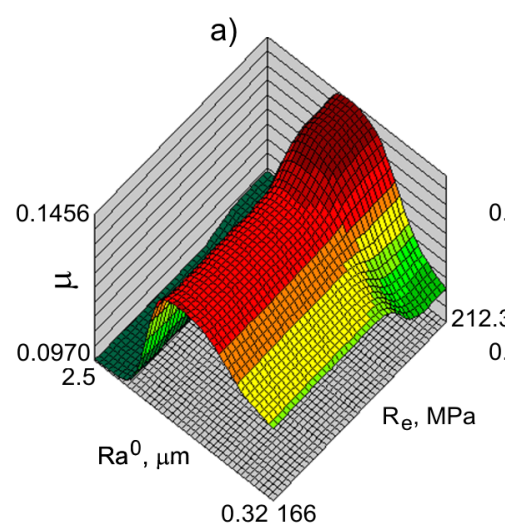

$$
0.32166
$$

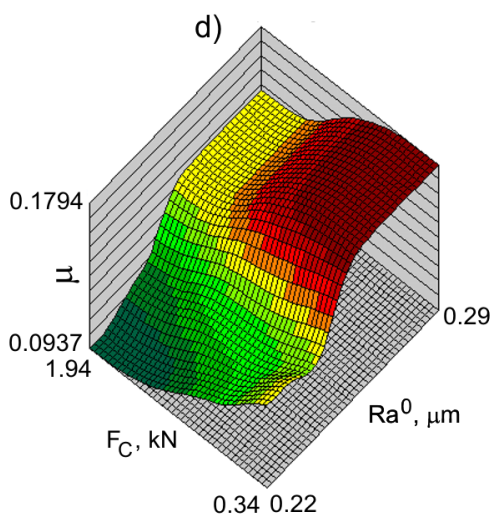

b)

0.340 .22

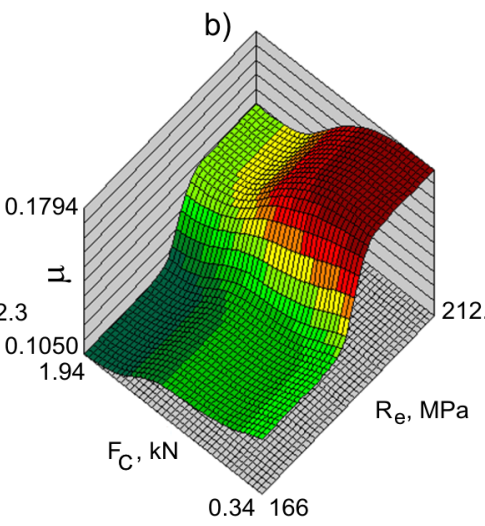

e)

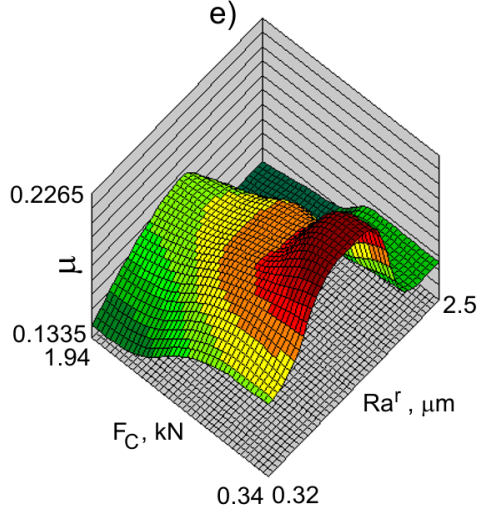

0.340 .32

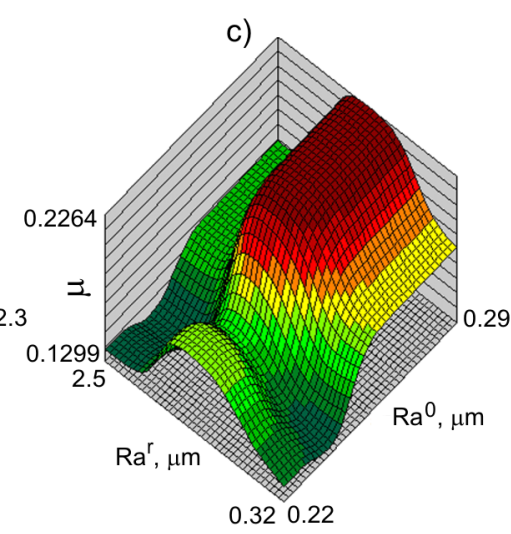

$0.32 \quad 0.22$

Fig. 4. Response surfaces presented the effect of different combinations of input parameters on the friction coefficient value 
a)

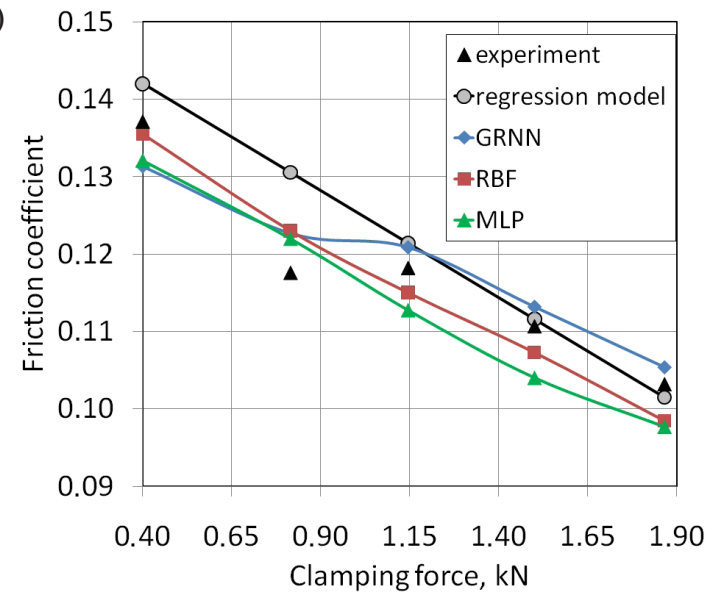

b)

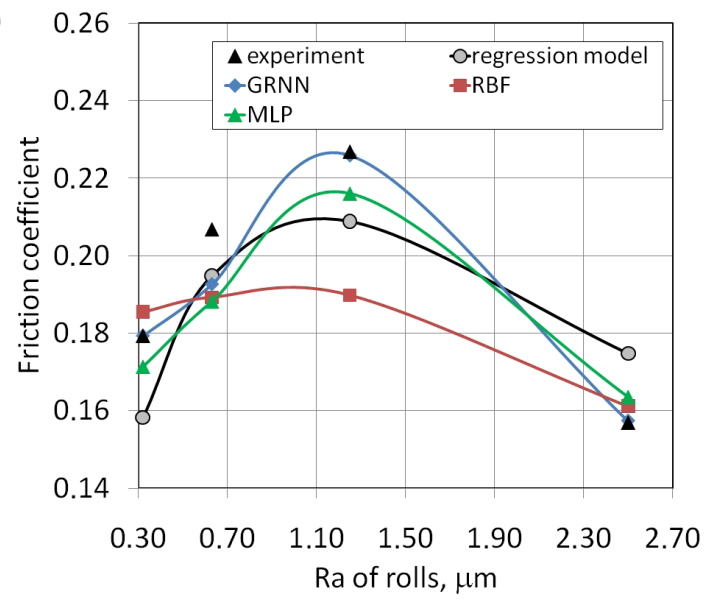

Fig. 5. Comparison of friction coefficient value determined experimentally, by regression and ANN model for: a) AA5754 H18 sheet metal $\left(\mathrm{Ra}^{\mathrm{r}}=0.63 \mu \mathrm{m}\right)$; b) AA5754 H14 sheet metal $\left(\mathrm{F}_{\mathrm{C}}=0.4 \mathrm{kN}\right)$

Evaluation of neural network model should take into account both the ability to approximation and generalization. Taking into account only the errors obtained for the training set usually prefers complex models, matching to the training data, but not having the skills to generalize the knowledge. Observation and closer analysis of response surfaces indicate that:

- for the $\mathrm{Ra}^{0}$ parameter in the range of $0.32-1.25$ $\mu \mathrm{m}$, an increase of the parameter value causes the friction coefficient value to increase (Fig. 4a). After exceeding the value of $1.25 \mu \mathrm{m}$, the friction coefficient starts to decrease,

- a decrease of clamping force value and simultaneously the yield stress causes a decrease of the coefficient of friction value (Fig. 4b),

- there is no evident effect of $\mathrm{Ra}^{0}$ parameter value on the friction coefficient value (Fig. 4c),

- a decrease of clamping force value and simultaneously the $\mathrm{Ra}^{0}$ roughness parameter causes a decrease of the coefficient of friction value (Fig. 4d),

- the maximum value of friction coefficient is observed for $\mathrm{Ra}^{\mathrm{r}}=1.25 \mu \mathrm{m}$, in the case of higher and lower values of $\mathrm{Ra}^{\mathrm{r}}$ the friction coefficients start to decrease (Fig. 4e).

The high value of Pearson's correlation coefficient $R$ and simultaneously low value of S.D. ratio for training set testify good approximation properties of the neural network. Comparison of regression and neural models (Fig. 5a and Fig. $5 b)$ illustrates a better fitting of neural network models to experimental data that are nonlinear. The best fit of ANN and experimental data is observed for GRNN.

\section{CONCLUSIONS}

Although the ANN model better fits the experimental data than the regression model it does not mean the resignation of an application of classical multiple regression. It should be pointed out that the predicted values have to be situated for the range of used values in the building procedure of the regression model. In case of possibly making a choice between the simple and the complex model the simple model should be preferred unless the other approximate data is much better. Based on the results of experiments and neural analyses the main conclusions are as follows:

- in the case of MLP network the highest performance is received for the network trained using BP algorithm,

- in the case of the RBF network the Conjugate Gradients algorithm was the most efficient training method,

- the best performance of the neural model is observed for GRNN,

- a decrease of clamping force value and simultaneously the yield stress causes a decrease of the coefficient of friction value,

- an increase of $\mathrm{Ra}^{0}$ roughness parameter of sheet metal leads to an increase of the friction coefficient value.

\section{REFERENCES}

1. Aleksendrić D., Barton D.C. and Vasić B. Prediction of brake friction materials recovery performance using artificial neural networks. Tribology International, 43(11), 2010, 2092-2099. 
2. Allison P.D. Multiple regression: A primer pine forge press series in research methods and statistics. SAGE Publications Ltd., 1999.

3. Bariani P.B., Bruschi S. and Dal Negro T. Prediction of nickel-base superalloys' rheological behaviour under hot forging conditions using artificial neural networks. Journal of Materials Processing Technology, 152(3), 2004, 395-400.

4. Cohen J., Cohen P., West S.G. and Aiken L.S. Applied multiple regression/correlation analysis for the behavioral sciences. Lawrence ERLBAUM Associates, 2003.

5. Dasgupta R., Thakur R. and Govindrajan B. Regression analysis of factors affecting high stress abrasive wear behaviour. Journal of Failure Analysis and Prevention, 2(2), 2002, 65-68.

6. de Souza T. and Rolfe B. Multivariate modelling of variability in sheet metal forming. Journal of Materials Processing Technology, 203(1-3), 2008, 1-12.

7. Dutta P. and Pratihar D.K. Modeling of TIG welding process using conventional regression analysis and neural network-based approaches. Journal of Materials Processing Technology, 184(1-3), 2007, 56-68.

8. Gyurova L.A. and Friedrich K. Artificial neural networks for predicting sliding friction and wear properties of polyphenylene sulfide composites. Tribology International, 44(5), 2011, 603-609.

9. Kasperkiewicz J. The application of ANNs in certain-analysis problems. Journal of Materials Processing Technology, 106(1-3), 2000, 74-79.

10. Kleinbaum D.G., Kupper L.L. and Muller K.E. Applied regression analysis and other multivariable methods. PWS Publishing Co., 1988.

11. Kumar P., Jain S.C. and Ray S. Study of surface roughness effects in elastohydrodynamic lubrication of rolling line contacts using a deterministic model. Tribology International, 34(10), 2001, 713-722.

12. Kurra S., Rahman N.H., Regalla S.P. and Gupta A.K. Modeling and optimization of surface roughness in single point incremental forming process. Journal of Materials Research and Technology, 4(3), 2015, 304-313.

13. Lemu H.G. and Trzepieciński T. Numerical and experimental study of frictional behaviour in bending under tension test. Strojniski Vestnik-Journal of Mechanical Engineering, 59(1), 2013, 41-49.
14. Li W. Manufacturing process diagnosis using functional regression. Journal of Materials Processing Technology, 186(1-3), 2007, 323-330.

15. Ma B., Tieu A.K., Lu C. and Jiang Z. A finiteelement simulation of asperity flattening in metal forming. Journal of Materials Processing Technology, 130-131, 2002, 450-455.

16. Myant C., Spikes H.A. and Stokes J.R. Influence of load and elastic properties on the rolling and sliding friction of lubricated compliant contacts. Tribology International, 43(1-2), 2010, 55-63.

17. Popko A., Jakubowski M. and Wawer R. Membrain neural network for visual pattern recognition. Advances Science and Technology Research Journal, 7(18), 2013, 54-59.

18. Powroźnik P. Polish emotional speech recognition using artificial neural network. Advances Science and Technology Research Journal, 8(24), 2014, 24-27.

19. Rapetto M.P., Almqvist A., Larsson R. and Lugt P.M. On the influence of surface roughness on real area of contact in normal, dry, friction free, rough contact by using a neural network. Wear, 266(5-6), 2009, 592-59.

20. Stachowicz F. and Trzepieciński T. Zastosowanie sieci neuronowych do wyznaczania współczynnika tarcia podczas kształtowania blach. Informatyka w Technologii Materiałów, 4, 2004, 87-97.

21. Trzepieciński T. Zastosowanie regresji wielokrotnej i sieci neuronowej do modelowania zjawiska tarcia. Zeszyty Naukowe Wyższej Szkoły Informatyki, 9(3), 2010, 31-43.

22. Statistica Neural Networks, Addendum for version 4. StatSoft, 1999.

23. Trzepieciński T. and Lemu H.G. Application of genetic algorithms to optimize neural networks for selected tribological tests. Journal of Mechanics Engineering and Automation, 2, 2012, 69-76.

24. Trzepieciński T. and Lemu H.G. Investigation of anisotropy problems in sheet metal forming using finite element method. International Journal of Material Forming, 4(4), 2011, 357-369.

25. Yetim A.F., Codur M.Y. and Yazici M. Using of artificial neural network for the prediction of tribological properties of plasma nitrided $316 \mathrm{~L}$ stainless steel. Materials Letters, 158, 2015, 170-173. 